14.06

\title{
Использование микроструктурированных подложек, полученных методом ионной имплантации, для подсчета бактерий
}

\author{
() В.Г. Евтюгин, ${ }^{1,2}$ А.М. Рогов, ${ }^{1,2}$ Л.Р. Валеева, ${ }^{1}$ В.И. Нуждин, ${ }^{2}$ А.Л. Степанов ${ }^{2}$ \\ ${ }^{1}$ Казанский федеральный университет, \\ 420008 Казань, Россия \\ ${ }^{2}$ Казанский физико-технический институт им. Е.К. Завойского, \\ Федеральный исследовательский центр - Казанский научный центр РАН, \\ 420029 Казань, Россия \\ e-mail: vevtugyn@gmail.com
}

Поступило в Редакцию 27 декабря 2019 г.

В окончательной редакции 27 декабря 2019 г.

Принято к публикации 17 февраля 2020 г.

\begin{abstract}
Описан новый технологический подход для создания методом ионной имплантации наноструктурированных подложек для визуальной характеризации сверхмалых биологических объектов и микроорганизмов. При использовании имплантации ионами аргона покровных силикатных стекол через маски в виде проволочных медных сеток на их поверхности были сформированы периодические микроструктуры в виде решеток с размерами ячеек $50 \times 50 \mu \mathrm{m}$. Апробация новых типов подложек была проведена на примере осажденных на них бактерий родов Bacillus и Staphylococcus методами сканирующей электронной микроскопии и энергодисперсионного анализа, а также атомно-силовой микроскопии.
\end{abstract}

Ключевые слова: микроструктурированные подложки, ионная имплантация, аналитическая микроскопия, микроорганизмы.

DOI: 10.21883/JTF.2020.09.49691.430-19

\section{Введение}

Микро- и наноструктурированные подложки могут быть применены для проведения счетного статистического анализа, а также для исследований в биомедицине при секвенировании, разделении, обнаружении, идентификации, количественном и структурном анализе микрообъектов таких, как клеточные популяции (кровь, клеточные культуры), микроорганизмы, вирусы и др.

Одним из возможных решений проблем своевременного выявления и последующей локализации распространения, а также диагностики различного вида инфекционных заболеваний является современная оперативная диагностика разнообразных биообъектов. Для этого все чаще привлекаются современные методы с использованием высокоразрешающей электронной и зондовой микроскопии. Быстрое развитие методов микроскопии происходит благодаря появлению новой приборной базы и использованию современных т ехнологических достижений при разработке новых композитных материалов, полученных на основе исследования их химических и физических свойств [1]. Создание принципиально новых контролирующих и анализирующих систем, а также разработка новых методов и методик на их основе могут быть успешно использованы в диагностике и характеризации биологического материала предельно малого размера (бактериальных клеток и вирусов). Поэтому появляются возможности, ранее не применявшиеся на практике, для их подсчета и статистической обработки, анализа формы и т.д. Все это позволяет значительно ускорить и упростить диагностику, а также анализ патогенного и условно патогенного биоматериала, что приближает переход к персонифицированной медицине и улучшению здравоохранения.

Целью настоящей работы является разработка, создание и проверка специфических регулярных микроструктурированных подложек (устройств) для осаждения на них и проведения подсчета сверхмалых биологических микрообъектов, в частности бактерий, методами высокоразрешающей электронной и зондовой микроскопии. Для создания таких биологических устройств предлагается применить технологию ионной имплантации, в частности, модификации и контролируемого структурирования поверхности различных подложек. Ионная имплантация в настоящее время является одной из базовых методик, применяющихся в промышленной полупроводниковой микроэлектронике для создания различных типов оптоэлектронных нано- и микроустройств [2]. Ранее была продемонстрирована возможность создания периодических поверхностных оптических дифракционных структур методами имплантации различными ионами через маски на таких материалах, как кремний [3], кварцевое стекло [4-6], полиметилметакрилат [7], алмаз [8]. Известны также работы по применению ионного травления при имплантации для контролируемого создания профилей, трехмерных объектов и микроструктур на поверхности металлов и полупроводников [9], к которым относится, в частности, технология травления фокусируемым ионным пучком в вакууме [10]. 

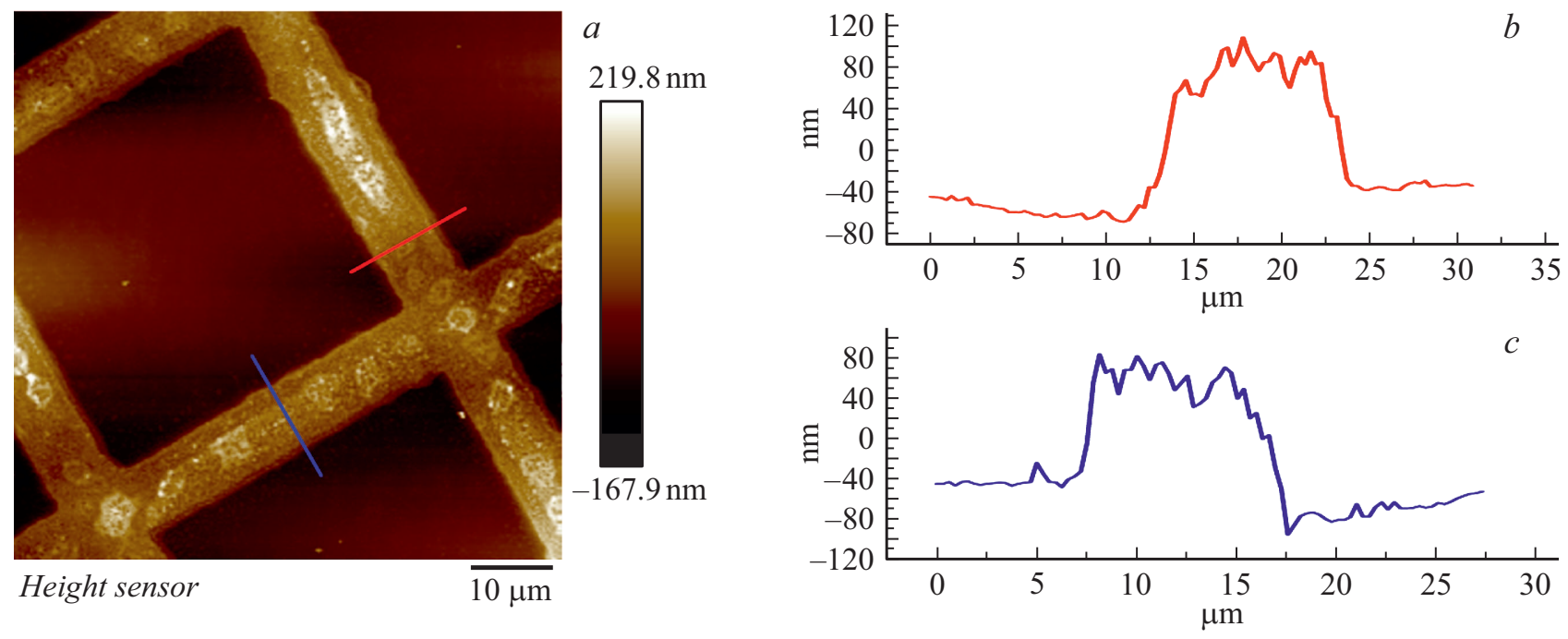

Рис. 1. АСМ-изображение $(a)$ и профили стенок ячеек поверхностной решетки $(b, c)$, измеренные по выделенным на фрагменте $(a)$ направлениям.
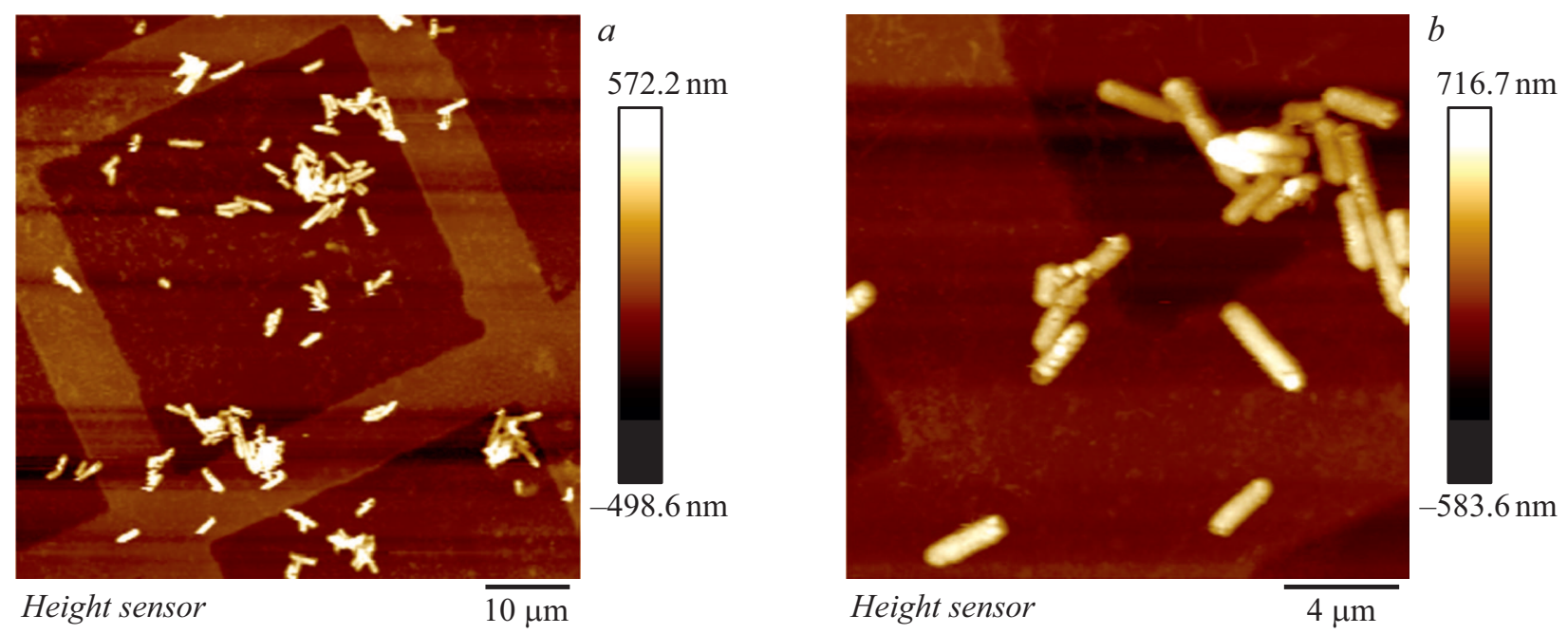

Рис. 2. АСМ-изображения в различных масштабах отдельной ячейки поверхностной решетки с нанесенными на нее бактериями Bacillus subtilis: $a$ - суспензия клеток, осажденная на подложку, $b-$ отдельные клетки бактерий в ячейке и на ребре сетки.

В настоящей работе впервые предполагается использовать имплантацию ионами инертного газа силикатного стекла через маску для формирования поверхностных микроструктур, применимых для использования в анализе сверхмалых биологических объектов.

\section{1. Методика эксперимента}

Имплантация однозарядными ионами аргона (энергия $E=40 \mathrm{keV}$, доза облучения $D=3.1 \cdot 10^{17} \mathrm{ion} / \mathrm{cm}^{2}$ и плотность тока в ионном пучке $J=20 \mathrm{mkA} / \mathrm{cm}^{2}$ ) проводилась на ионнолучевом ускорителе ИЛУ-3 через проволочную медную маску-сетку в покровные силикатные стекла $(20 \times 20 \mathrm{~mm}$, толщина $170 \mu \mathrm{m})$.

Морфологию структурируемой поверхности имплантированного стекла с нанесенными микроорганизмами исследовали методом растровой электронной микроскопии (РЭМ), при этом использовался автоэмиссионный сканирующий электронный микроскоп высокого разрешения Merlin (Carl Zeiss) при низком ускоряющем напряжении $5 \mathrm{keV}$ в режиме детектирования вторичных электронов. Метод атомно-силовой микроскопии (ACM; атомно-силовой микроскоп Dimension Fast Scan (Bruker)) также был применен для исследования морфологии структурируемой поверхности при использовании с зондами Bruker ScanAssyst Air, радиус закругления $\sim 5 \mathrm{~nm}$ и жесткость $0.4 \mathrm{~N} / \mathrm{m}$. Элементный анализ проводился с помощью энергодисперсионного (ЭДС) спектрометра X-Max (Oxford Instruments), используемого в комплексе с РЭМ при ускоряющем напряжении $20 \mathrm{keV}$. 

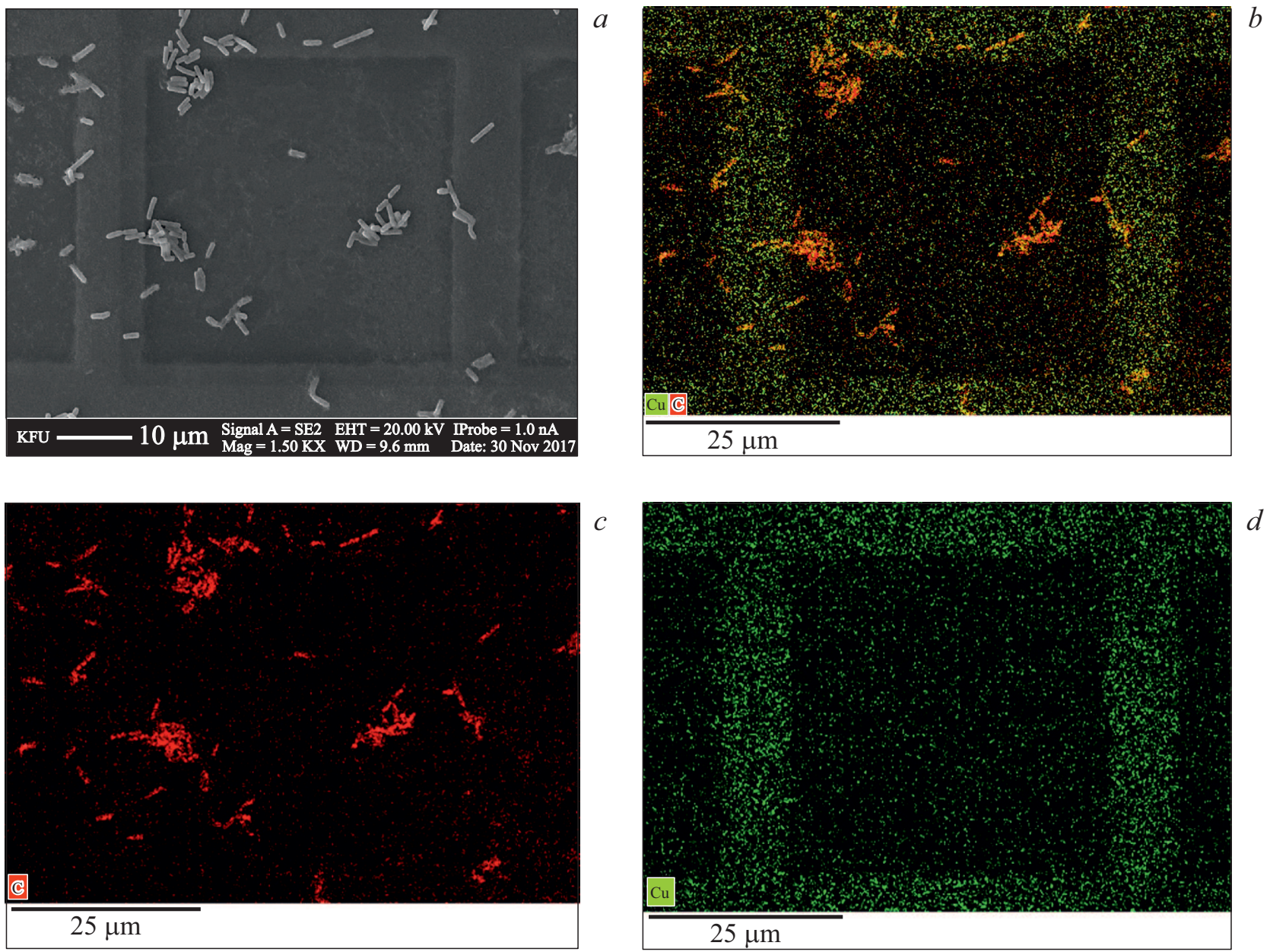

Pис. 3. РЭМ-изображение отдельной ячейки поверхностной решетки $(a)$ с нанесенными на нее бактериями Bacillus subtilis, соответствующие ей ЭДС-карты для различных химических элементов: углерод + медь $(b)$, углерод $(c)$, медь $(d)$.

В качестве биологического материала для осаждения на предлагаемые подложки использовали штаммы бактерий Bacillus subtilis MG4 и Staphylococcus aureus subsp. aureus Rosenbach (ATCC 2592) из коллекции микроорганизмов лаборатории биосинтеза и биоинженерии ферментов Института фундаментальной медицины и биологии Казанского федерального университета. Культивирование бактерий проводили на жидких питательных средах LB (Luria-Bertani): триптон - $10 \mathrm{~g} / \mathrm{l}$, дрожжевой экстракт $-5 \mathrm{~g} / 1$, хлорид натрия $\mathrm{NaCl}-5 \mathrm{~g} / 1$. Культивирование проводили при температуре $37^{\circ} \mathrm{C}$, при перемешивании 200-250 rpm в течение $16-18 \mathrm{~h}$. Впоследствии суспензия микроорганизмов осаждалась центрифугированием (5000 rpm, центрифуга Biosan), ocaдок ресуспендировали в 1\%-глутаровом альдегиде (ЕМ grade, Sigma-Aldrich) и выдерживался в течение $18 \mathrm{~h}$ для прохождения химической фиксации. После процедуры химической фиксации микроорганизмы осаждали центрифугированием и отмывали в фосфатном буфере, далее проводилось обезвоживание в этиловом спирте (50-96\%). Из 96\%-спирта суспензия осаждалась, наносилась на микроструктурированную ионной имплан- тацией стеклянную подложку. Для проведения РЭМ и ЭДС-анализа на поверхность подложки с бактериями наносился проводящий слой золото/палладий (Quorum Q-150T ES) толщиной 10-15 nm.

\section{2. Результаты и их обсуждение}

Ионная имплантация является процессом внедрения ускоренных ионов в облучаемую матрицу на определенную глубину в зависимости от энергии. Процесс столкновения ионов с поверхностью может сопровождаться ее частичным распылением. Характер распыления зависит от ряда факторов: энергия ускорения, масса иона, плотность вещества мишени и т.д. Если проводится имплантация материала через маску, то на его поверхности образуются облученные области, соседствующие с необлученными участками. В определенных случаях, например при высокодозовой имплантации монокристаллических подложек алмаза ионами бора [7], облученные участки превращаются в пористый графит, которые распухают и возвышаются над исходным уров- 

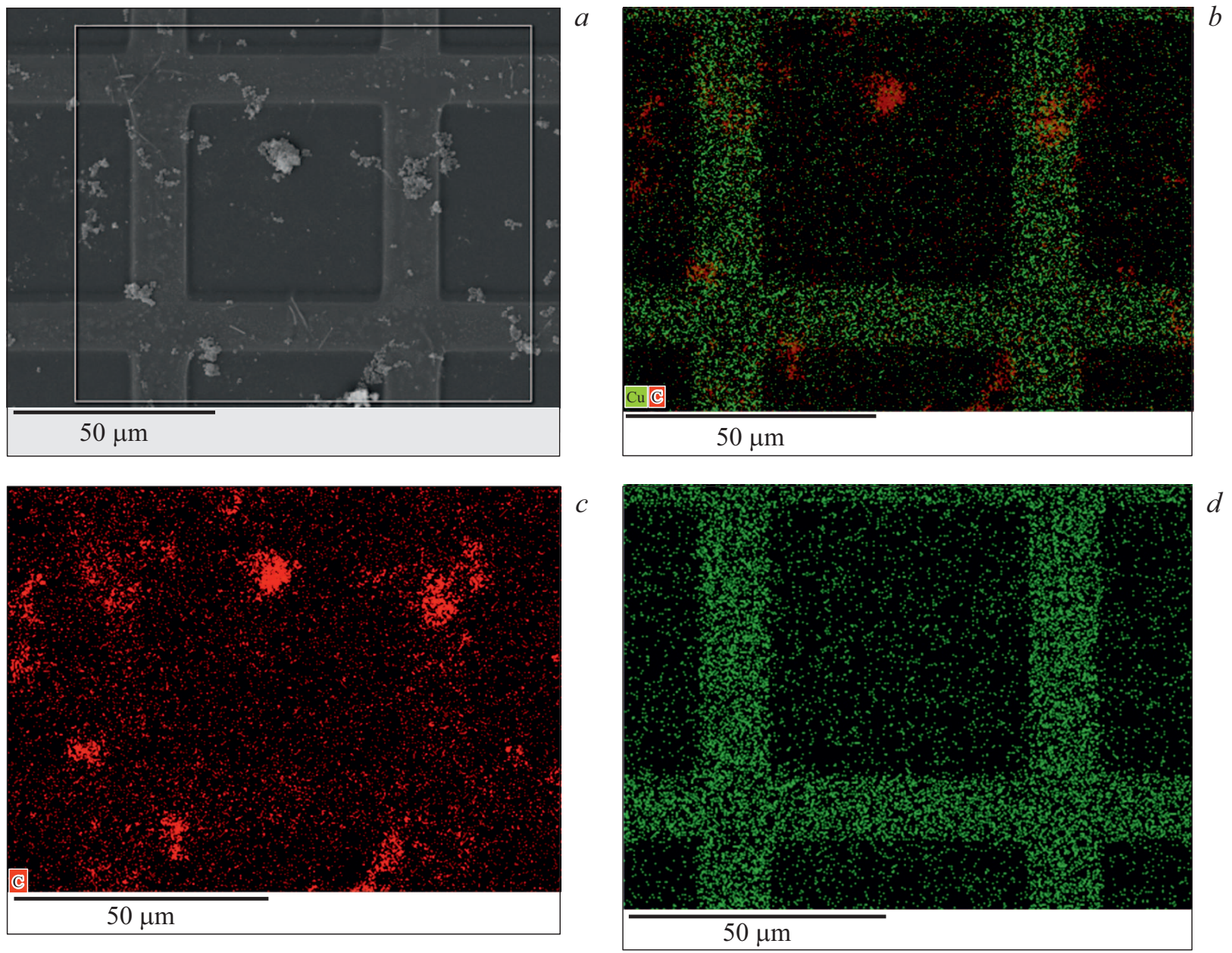

Рис. 4. РЭМ-изображение отдельной ячейки поверхностной решетки $(a)$ с нанесенными на нее бактериями Staphylococcus ep., соответствующие ей ЭДС-карты для различных химических элементов: углерод + медь $(b)$, углерод $(c)$, медь $(d)$.

нем подложки. Напротив, при имплантации кварцевого стекла ионами металлов наблюдалось его распыление и понижение уровня облученного участка относительно поверхности исходной подложки [4,5].

В настоящей работе наблюдение изменения морфологии поверхности силикатного стекла, подвергнутого высокодозовой имплантации ионами аргона через маску, проводилось методом АСМ. На рис. 1, $a$ приведено АСМ-изображение микроструктурированной поверхности стекла, которое отображается в виде сетки. Толщина распыленного слоя стекла (глубина ячеек решетки) для использованной дозы облучения составляет $60-80 \mathrm{~nm}$, о чем свидетельствуют приведенные на рис. $1, b$, с профили, измеренные на стенках ячеек. При этом ширина ячейки решетки составляет $50 \mu \mathrm{m}$. На рис. 2, $a$ показаны ACM-изображения той же решетки на стеклянной подложке после нанесения на нее бактерий рода Bacillus. Хорошо видно, что размерные параметры сформированных структур обеспечивают удобное соотношение для работы с микроорганизмами, в частности бактериями средних $(3-5 \mu \mathrm{m})$ размеров. Как следует из рис. $2, b$, часть бактерий осаждается на ребрах решетки, что мо- жет приводить к некоторой ошибке при статистическом анализе распределения биоматериала по площади. Очевидно, что использование более длительной по времени ионной имплантации приводит к формированию более глубоких ячеек решетки, что может позволить изолировать бактерии, локализованные на ребрах решетки, от поверхности дна ячеек и исключить эти бактерии из общего анализа микроорганизмов.

На рис. 3, $a$, 4, $a$ представлено РЭМ-изображение бактерий, нанесенных в небольшой концентрации на микроструктурированную подложку и регистрированных на фоне отдельной ячейки. Наблюдается относительно равномерное распределение бактерий по всей поверхности имплантированного стекла, преимущественно в углублениях ячеек. Видно, что размеры клеток являются типичными как для представителей вида Bacillus subtilis в вегетативном физиологическом состоянии: длина клеток составляет 3-5 $\mu \mathrm{m}$, ширина $-1 \mu \mathrm{m}$, так и для представителей вида Staphylococcus aureus: сферические клетки $2-3 \mu \mathrm{m}$ в диаметре. Методом ЭДС (рис. $3,4, b-d$ ) показано, что при использовании картирования по химическим элементам за счет детектирования характе- 
ристического рентгеновского излучения на поверхности стекла можно наблюдать периодические облученные и необлученные области в виде решетки, соответствующей размеру маски-сетки. В частности, на рис. $3,4, d$ отчетливо прослеживается распределение меди в виде решетки, которая сформи рована при диффузии меди в стекло из нагретой ионным током маски. На другом примере (рис. 3,4,c) показано, как расположение бактерий может регистрироваться по карте распределения углерода. Нанесенные бактерии при этом наблюдаются на фоне медной решетки, на фоне которой достаточно удобно детектировать и анализировать распределение бактерий по сигналу элемента - углерода. Это достигается при наложении ЭДС-карт меди и углерода (рис. 3,b). Иными словами, становится возможным оценить плотности упаковки осажденных бактериальных клеток даже при отсутствии различимой визуально профильного геометрического СЭМ-изображения решеточной структуры подложки в детекторе вторичных электронов. Данный подход по ЭДС-картированию может позволить работать не только с малыми концентрациями биологического материала, но также и с их толстыми слоями, поскольку электронный пучок проникает через них достаточно глубоко в объем образца.

\section{Заключение}

Таким образом, в работе продемонстрирована возможность разработки и создания принципиально новых технологических анализирующих систем (в частности микроструктурированных стеклянных подложек), а также заложена основа для разработки новых методик характеризации клеточного материала малого размера на основе АСМ-, РЭМ- и ЭДС-анализа. Использование микроструктурированных подложек с периодической ячеистой структурой, сформированной методом ионной имплантации через маску, позволяет вести подсчеты на сложных свермалых биологических микрообъектах. Большая глубина проникновения электронов в органические среды при ЭДС-картировании позволяет получить изображение сформированной решетки даже из-под плотного слоя биологического материала, что существенно расширяет возможности анализа микробных биопленок.

\section{Благодарности}

Автор благодарит Междисциплинарный центр „Аналитическая микроскопия“ КФУ за возможность проведения анализов методами атомно-силовой и сканирующей электронной микроскопии.

\section{Конфликт интересов}

Авторы заявляют, что у них нет конфликта интересов.

\section{Список литературы}

[1] Альперин П.М. Камеры счетные. Большая медицинская энциклопедия. Т. 12. 2-е изд. М.: Советская энциклопедия, 1959. C. $57-65$.

[2] Stepanov A.L. Ion implantation synthesis and optics of metal nanoparticles. Mauritius: Lambert Acad. Publ., 2018. 437 p.

[3] Azimi S., Breese M.B.H., Dang Z.Y., Yan Y., Ow Y.S., Bettiol A.A. // J. Micromech. Microeng. 2012. Vol. 22. P. 15015.

[4] Stepanov A.L., Galyautdinov M.E., Evlyukhin A.B., Nuzhdin V.I., Valeev V.F., Osin Y.N., Kiyan R., Kavetskyy T.S., Chichkov B.N. // Appl. Phys. A. 2013. Vol. 111. P. 261.

[5] Can-Uc B., Rangel-Rojo R., Marquez H., RodriguezFernandez L., Oliver A. // Opt. Express. 2015. Vol. 23. N 3. P. 3176.

[6] Wang J., Mu X., Wang G., Liu C. // Opt. Mater. 2017. Vol. 73. P. 466.

[7] Нужсди В.И., Валеев В.Ф., Галяутдинов М.Ф., Осин Ю.Н., Степанов А.Л. // Квант. электрон. 2018. T. 48. № 1. C. 82.

[8] Степанов А.Л., Нуждин В.И., Галяутдинов М.Ф., Курбатова Н.В., Валеев В.Ф., Воробьев В.В., Осин Ю.Н. // Письма в ЖТФ. 2017. Т. 43. Вып. 2. С. 38.

[9] Azimi S., Breese M.B.H., Dang Z.Y., Yan Y., Ow Y.S., Bettiol A.A. // J. Micromech. Microeng. 2012. Vol. 22. P. 15015.

[10] Atiqah N., Jaafar I.H., Ali M.Y., Asfana B. // Adv. Mater. Res. 2012. Vol. 576. P. 507. 